\section{Wind Tunnel Testing of Powered Lift, All-Wing STOL Model}

\author{
Scott W. Collins and Bryan W. Westra \\ Northrop Grumman Corporation, El Segundo, CA \\ John C. Lin and Gregory S. Jones \\ NASA Langley Research Center, Hampton, Virginia \\ Cale H. Zeune \\ Air Force Research Laboratory, Wright-Patterson \\ $\mathrm{AFB}, \mathrm{OH}$
}

\begin{abstract}
Short take-off and landing (STOL) systems can offer significant capabilities to warfighters and, for civil operators thriving on maximizing efficiencies they can improve airspace use while containing noise within airport environments. In order to provide data for next generation systems, a wind tunnel test of an all-wing cruise efficient, short take-off and landing (CE STOL) configuration was conducted in the National Aeronautics and Space Administration (NASA) Langley Research Center (LaRC) 14- by 22-foot Subsonic Wind Tunnel. The test's purpose was to mature the aerodynamic aspects of an integrated powered lift system within an advanced mobility configuration capable of $\mathrm{CE}$ STOL. The full-span model made use of steady flap blowing and a lifting centerbody to achieve high lift coefficients. The test occurred during April through June of 2007 and included objectives for advancing the state-of-the-art of powered lift testing through gathering force and moment data, on-body pressure data, and off-body flow field measurements during automatically controlled blowing conditions. Data were obtained for variations in model configuration, angles of attack and sideslip, blowing coefficient, and height above ground. The database produced by this effort is being used to advance design techniques and computational tools for developing systems with integrated powered lift technologies.
\end{abstract}

\section{Technology Need}

Mobility aircraft are the workhorses of today's air force. They provide the means to deliver critical supplies to operating units dispersed around the globe. Being able to quickly, efficiently, and reliably transport associated payloads will be a key in successful, future military operations.

The conflicts that the U.S. military now engages in are fundamentally different than those from which design requirements were established for current military mobility aircraft such as the $\mathrm{C}-130$ and $\mathrm{C}-17$. These were primarily designed to be used in a conventional, linear war where they generally transported troops and materiel supplies between established bases with hard-surfaced runways.

Recent conflicts have consisted primarily of operations against non-linear, amorphous, asymmetric adversaries and so require the warfighter to be flexible and responsive in employing forces to counter such opposition. Furthermore, modern militaries must be able to conduct counter-insurgency operations while also maintaining capabilities for high intensity combat. The ability to rapidly deploy mounted, armored ground forces near to the point of action is crucial to being successful in today's environment. In fact, the U.S. military has shifted from more traditional approaches to enable modular methods of operation. The United States Air Force (USAF) now comprises Air Expeditionary Force (AEF) units that are deployed from the U.S. to quickly commence combat operations. Critical to this force construct is flexible transport aircraft that deploy, maneuver, and sustain the ground troops through both theater and strategic airlift.

Research initiatives underway are directed at identifying systems and technologies that fill theater and strategic airlift needs in a single system. To that end, Northrop Grumman, NASA, and the Air Force Research Laboratory (AFRL) collaborated to mature integrated high lift technologies and an aircraft configuration to meet emerging needs. A technology area demonstrating the ability to notably reduce the field length required to takeoff and land is circulation control. Several technology demonstrators, including Northrop Grumman's A-6/Circulation Control Wing (CCW) revealed this point several decades ago. ${ }^{1}$ Such historical programs also revealed that challenges remain in understanding the detailed flow physics of circulation control to ensure efficient integrate for safe, modern mobility aircraft. Additionally, more recent research indicates that such flow control techniques can do more than simply achieve high performance; they can offer simpler, lighter, and less costly systems than approaches employed on operational aircraft today. ${ }^{2}$ The application herein applies this technology to blown flaps on an all-wing air vehicle concept.

\section{Air Vehicle Concept and Test Objectives}

Given the inherent benefits of all-wing designs ${ }^{3}$, the aircraft concept studied in this effort leverages planform area while managing the risk in achieving the lift required for STOL operations. That is to say if a low to moderate wing loading is chosen for low conventional take-off and landing distances then the amount of additional lift required for STOL objectives is minimized and the corresponding sensitivity to the requirement is lower. In the 
approach studied here, the concept's centerbody produces one-third of the system's total lift while the wings with blown flaps produce the remaining twothirds. Suitable momentum thrust to power the flaps is obtained from the fan stage of the aircraft's engines. This air source minimizes the impact to vehicle thrust. It also benefits elements required for system redundancy to preserve the aircraft's STOL capabilities in the event of an engine out condition. With this highly integrated, all-wing design, the testing focused on substantiating lift performance and obtaining stability and control increments under blowing. Also of interest was the study of flow field physics to better aid design optimization.

\section{Facility Description}

The NASA Langley 14- by 22-Foot Subsonic Wind Tunnel is an atmospheric, closed return tunnel with a test section of 14.5 feet high, 21.75 feet wide, and 50 feet long that can reach a freestream velocity of 348 feet per second with a dynamic pressure of 144 pounds per square foot. The Reynolds number per foot ranges from 0 to $2.2 \times 10^{6}$. Test section airflow is produced by a 40 feet diameter, 9-bladed fan powered by a 12,000 horsepower solid-state converter with synchronous motor. The tunnel has a set of flow control vanes to maintain close control of the speed for low-speed testing. The closed test section configuration was used for the subject test, and the configuration produced relatively uniform flow with a velocity fluctuation of 0.1 percent or less.

\section{Model Description and Installation}

The test article was a full-span sting-mounted model termed HAWSTOL for High-speed, All Wing STOL (Figure 1). HAWSTOL was developed by Northrop Grumman for AFRL to advance integrated high-lift and control system technologies.

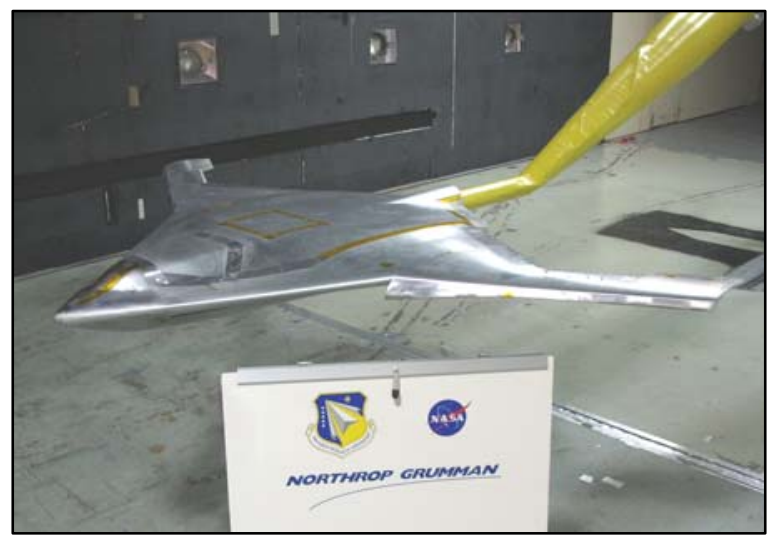

Figure 1. HAWSTOL Model in Langley 14' x 22' Subsonic Wind Tunnel
The model was a modification of an existing half span model previously tested in a $7 \times 10$ foot low speed wind tunnel. The left wing and associated hardware were reused from the previous half span model and a new right wing and center body were designed and fabricated for the full span test. The model included wing leading edge slats. During the prior testing a preferred leading edge slat location and orientation was identified. Therefore only the left wing slat could be set in one of four positions while the right contains mounting links for only the optimal position. The model also included various inboard and outboard wing trailing edge blown flaps (Figure 2). The blowing slot height was set at a fixed height-to-wing-chord ratio across the model. These flaps could separately be deflected to $-30,0$, 30,60 , or 90 degrees with positive angles corresponding to trailing edge down deflections.

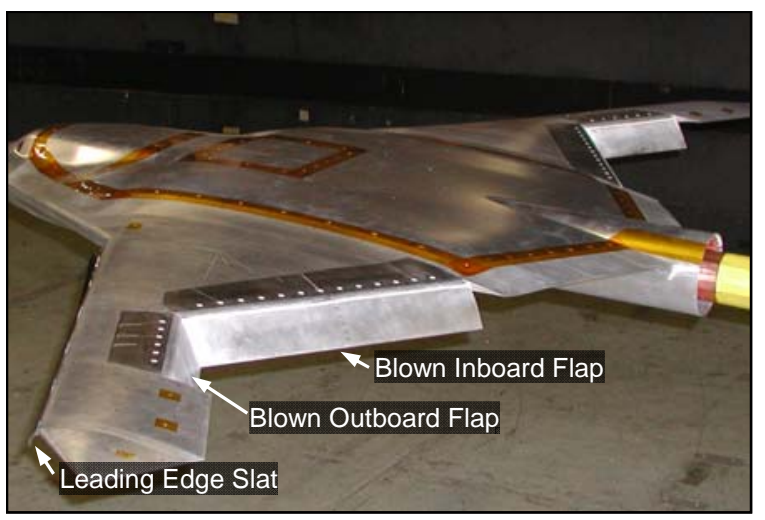

Figure 2. Model Shown with Leading Edge Device and All Flaps Deflected 60 degrees

NASA model support cart number seven was used to provide variations in pitch, yaw, and height. The support system is shown in Figure 3. Although it is preferable to test models by consistently positioning and rotating them about a model reference point fixed in the tunnel, this was not possible with available installation hardware. Thus pitch sweeps were performed at constant height over span $(\mathrm{h} / \mathrm{b})$ of 0.60 for pitch angles greater than 0 degrees as ground effects testing confirmed that wall effects were small at this height. For the minimum pitch angle of -3.5 degrees, $\mathrm{h} / \mathrm{b}$ was 0.56 and would increase until reaching 0.60 as the model was pitched up. Yaw angles from -20 degrees to +20 degrees were tested by rotating the facility mast. Thus the model traversed the tunnel (i.e., moved closer to the side-walls) as the center support mast was rotated. 


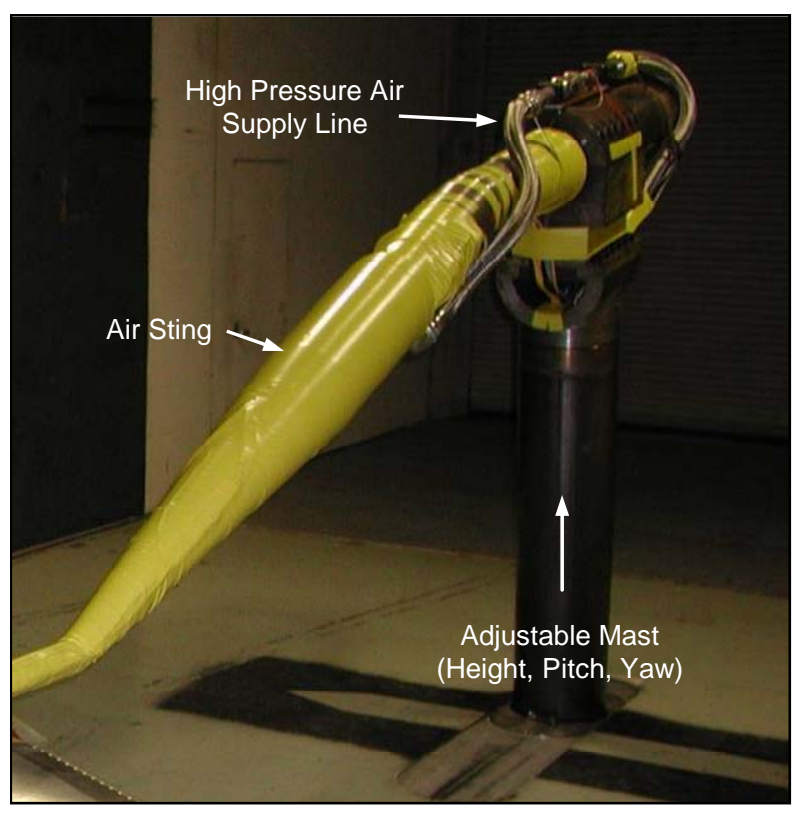

Figure 3. Model Support System Showing Air Supply to Sting

Provisions were included to detect model fouling on the support system and an internal Q-flex inclinometer device was used for model pitch measurement. The Langley balance 1621 was used to measure six component model forces and moments. Because of the high pressure air needs, the balance was used with the air-sting support system to provide a nonmetric to metric high-pressure air balance crossover. The system, shown in Figure 4 shows the metric components (air sting coil, accumulator, model, balance block, and balance).

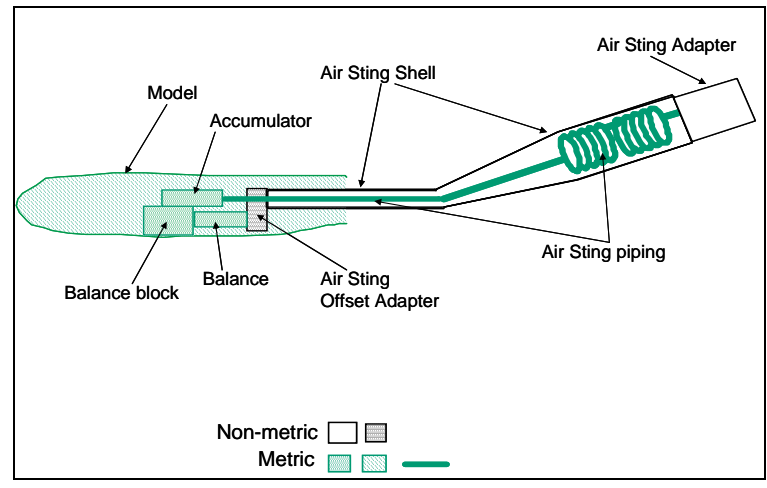

Figure 4. Installation Enabled Nonmetric to Metric High Pressure to Air Balance Crossover

The entire system, without the model, was calibrated prior to the test with and without pressure on the system. The effect of pressure was very small and was not used in the equations that calculate force and moments from raw gauge units. But during testing, a small correction based on accumulator pressure was calculated from run data with the model valves closed. The pressure correction was limited to axial force and pitching moment. The correction enabled better run repeatability with the highpressure system flowing and more accurate drag and pitching moment measurements. An additional correction was applied to normal force and pitching moment to address temperature gradients across the balance. This correction was also small and the temperature effect was minimized by warming the system prior to acquiring data.

Computational fluid dynamics (CFD) models were used to determine the appropriate application of grit for the model. Analyses concluded that No. 60 grit (0.0114 inches) located 1 inch normal from the leading edge on the inboard section of the model will adequately force transition. The outboard section of the wing was not gritted since the presence of the slat would force natural transition. The same grit size and location was applied to both the upper and lower surface.

\section{High Pressure Air and Flow Control System}

High pressure air at approximately 180 psig entered the model through a tube in the hollow support sting. This high pressure reduces tubing diameter and minimizes pressure loss, but requires choke plates near the blowing slot to drop pressure to design levels. This tube was connected to an accumulator that distributed air to the four high aspect-ratio wing blowing slots just forward of the wing flap. V-notch type, ball valves mounted to the accumulator were used to control the nozzle pressure ratio $(\mathrm{Pt} / \mathrm{Ps}$,inf) at each slot. The valves were connected to the blowing slot plenums by flexible tubing and stainless steel hardlines. Porous choke plates upstream of each slot were designed to provide a maximum nozzle pressure ratio (NPR) of 2.0 as well as to provide uniform spanwise NPR. The choke plates created a large pressure drop from the facility air supply to the set pressure at the slot nozzle. The choke plate was designed to reach sonic conditions for exit nozzle pressure ratios above approximately 1.03 . This provided a linear slot flow rate variation with pressure. The choke plates were calibrated and used as accurate flow meters for each slot resulting in a constant corrected mass flow $\left(\mathrm{W}_{\mathrm{COR}}\right)$ for the choked flow with $\mathrm{W}_{\mathrm{COR}}$ defined as:

$$
W_{C O R}=W\left(\frac{\sqrt{T_{O} / 518.7^{\circ} R}}{P_{O} / 14.696 p s i a}\right) .
$$

Here $\mathrm{W}$ is the measured mass flow in $\mathrm{lbm} / \mathrm{s}, \mathrm{T}_{\mathrm{O}}$ is the 
blowing jet total temperature in degree $\mathrm{R}$, and $\mathrm{P}_{\mathrm{O}}$ is the jet total pressure in psia. The corrected mass flow versus choke plate pressure ratio was curve fit and entered into a lookup table that was used during the test. The summation of all four calculated choke plate flows was compared against the facility flow meter with typical accuracy within $+/-2 \%$ for the test.

A closed-loop valve controller was developed to modulate the valves. The flow condition at the blowing slots was verified with a hand-held probe. These checks ensured that the choke plate seals functioned properly. Figure 5 shows data from a survey performed on the left inboard blowing slot at the start of the test.

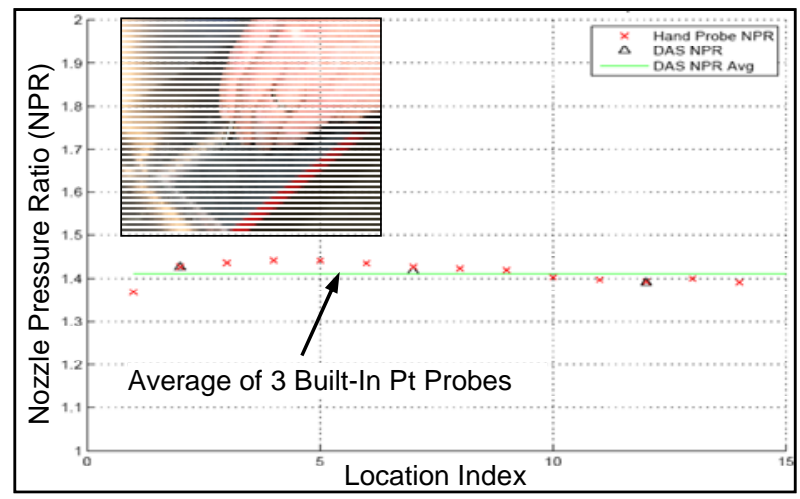

Figure 5. Sample Slot Total Pressure Survey

\section{Wall Corrections}

The reduction of the tunnel data followed standard NASA LaRC and Northrop Grumman wall corrections as two primary reductions were made. Northrop Grumman's corrections are based on methods used in the Hawthorne, California 7- by 10foot Low Speed Wind Tunnel; however, constants used for this entry were altered for the 14- by 22-foot test section geometry. The main purpose of having both sets of corrections on the data stream was to quantify differences, if any, between LaRC and Northrop Grumman parameters corrected for wall effects for this configuration type. The two methods provided similar results for corrected angles of attack and forces and moments but a small discrepancy in the drag coefficient was noted. The difference in methods related to the use of corrected or uncorrected angle of attack (AoA) to compute the corrected drag coefficient. The magnitude of the difference was approximately 1 count at 0 degree angle of attack and 18 counts at 10 degrees angle of attack. A third set of wall corrections, using the wall pressure signature method, were also generated by LaRC.

Data gathered during ground effect runs were corrected using the three-wall removal method whereby the floor (i.e. ground) effect remains.
Constants were calculated for heights over span ratios of $0.5,0.35$ and 0.20 and applied to the ground effects data following the three-wall method. Corrected data per Northrop Grumman and LaRC methods provided similar results as in the "free-air" corrected runs.

\section{Data Gathering Techniques and Results}

Four methods for gathering air-on data were employed during this test. Force and moment data were gathered from the installation's balance. Onbody pressure measurements were obtained from pressure taps distributed chordwise and spanwise about the vehicle. Additional pressure data were obtained through the application of pressure sensitive paint (PSP) applied to one side of the model. Finally, an off-body flow field survey was conducted using a 7-hole probe rake system for insights into complex interactions of the blowing jet and freestream flow. Sample data will be provided herein as more details are provided through separate papers on the respective techniques.

\section{Force and Moment Data}

Force and moment data were gathered using traditional balance techniques. Wind tunnel dynamic pressure was typically set at $30 \mathrm{psf}$ and pitch sweeps of -3.5 to 24 degrees were performed for angles of sideslip ranging from -20 to 20 degrees at increments of 5 degrees. The effects of single as well as combinations of multiple control surface deflections were obtained with blowing varied on the wing flaps by controlling slot nozzle pressure ratio. The following NPR conditions were tested with the corresponding blowing coefficient listed in parenthesis: 1.0 (blowing off), 1.05 (0.005), 1.20 (0.018), $1.40(0.034)$, and $1.6(0.048)$. Sweeps in sideslip were also made at select angles of attack and heights above ground of $0.2,0.35$, and 0.5 (where 0.6 was nominal) height over span $(\mathrm{h} / \mathrm{b})$ were evaluated.

As intended, blowing the inboard flap is the configuration's most effective lift enhancer. It benefits from considerable planform area to influence circulation and the surface's size is roughly twice that of the outboard flap. Figures 6 and 7 are provided to show the incremental lift coefficient obtained for deflections of a single inboard flap at 30 and 60 degrees trailing edge down respectively. For the lift data presented, coefficients are determined by normalizing the force with planform area.

These increments were created by subtracting the data for the condition shown from the data with undeflected flaps and a slot nozzle pressure ratio of unity (i.e. blowing off). This allows the reader to see both the effect of the flap itself and then the level of benefit achieved with blowing. 


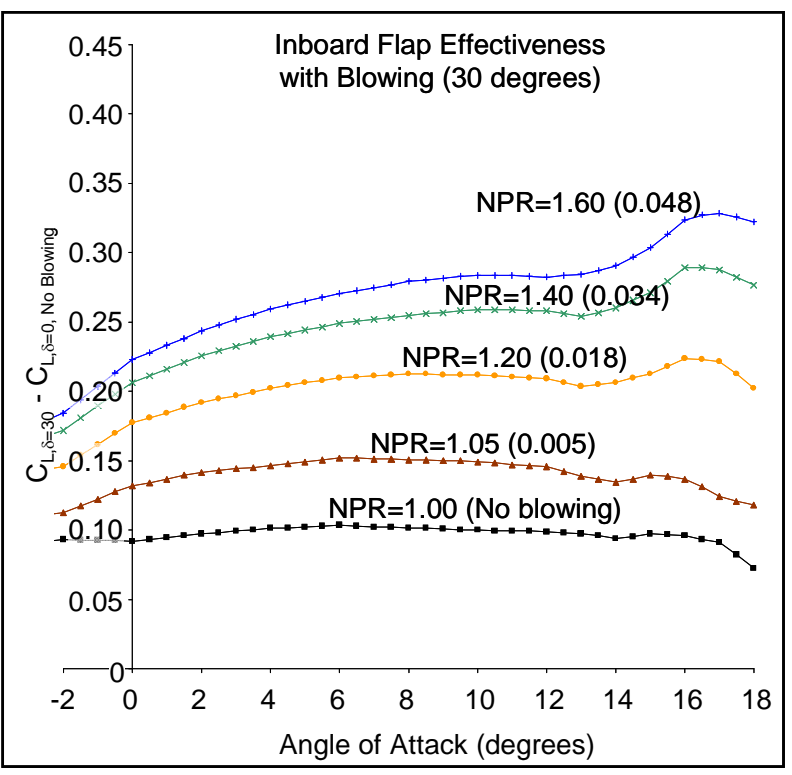

Figure 6. Effectiveness of Blowing on Increasing Single Inboard Flap Performance at 30 degrees Deflection

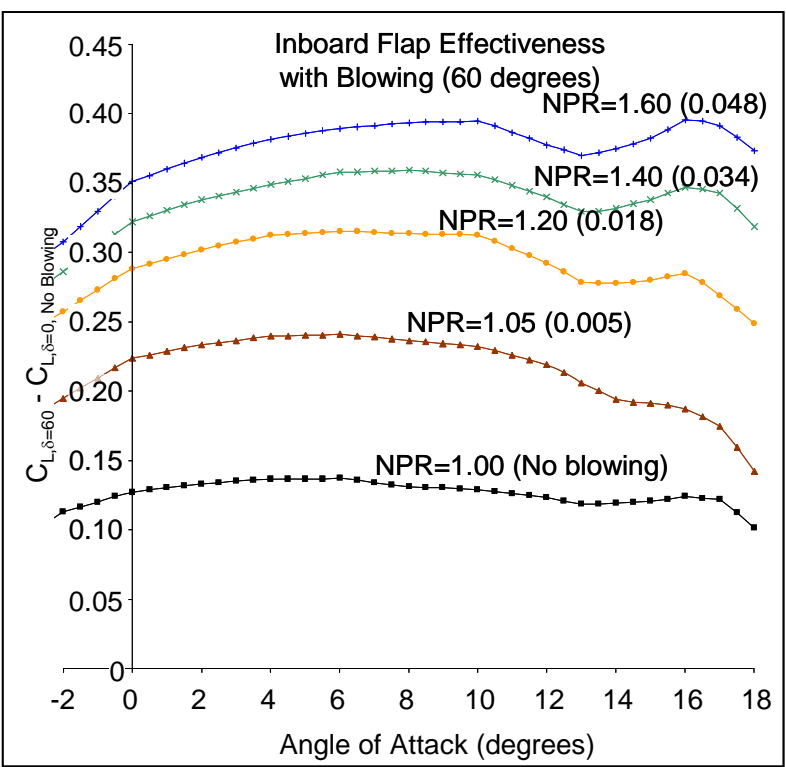

Figure 7. Effectiveness of Blowing on Increasing Single Inboard Flap Performance at 60 degrees Deflection

Generally simple, unblown flaps do not offer significant increases in lift effectiveness beyond 30 degrees deflection. With blowing off, doubling the flap deflection, i.e. deflecting the flap from 30 to 60 degrees, produced less than a 30 percent increase in additional effectiveness. Adding blowing to this three-dimensional configuration increased the effectiveness of both flap conditions with the 60 degree effectiveness increasing by as much as three times the 30 degree case. Similar trends were observed for the outboard flap.

At the air vehicle level, circulation control produced well behaved aerodynamic characteristics below 10 degrees angle of attack. Beyond this region, a vortex caused by the configuration's forebody interacts with the inboard flap. This caused an increase in flap effectiveness at 30 degrees deflection but a decrease in effectiveness at angles between 10 and 14 degrees for the 60 degrees deflection case. Alterations (not reported here) of the configuration eliminated this phenomenon.

In order to study ground effects the model was lowered to set points for pitch sweeps nearer the tunnel floor. As expected, the effectiveness of both the unblown and blown flaps was shown to increase. Beginning with two 60 degree deflected flap conditions from Figure 7, namely the non-blowing NPR of 1.0 and the blowing NPR of 1.40 conditions, Figure 8 presents lift increments for differing height over span ratio $(\mathrm{h} / \mathrm{b})$. As in Figure 7, these also were created by subtracting the baseline condition (undeflected flaps without blowing at a height over span ratio of 0.6 ) from the noted condition.

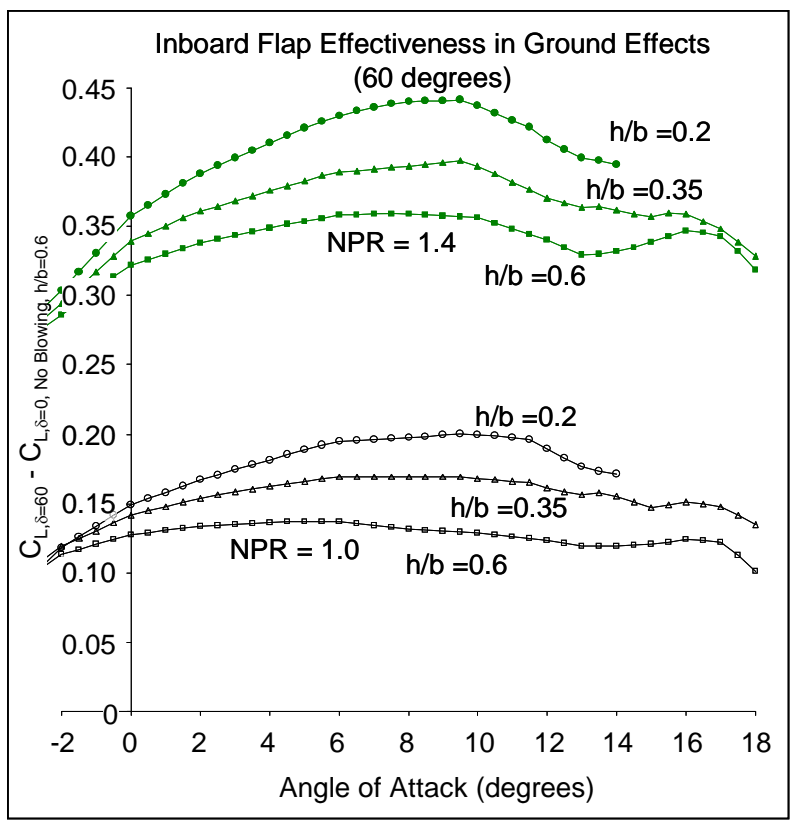

Figure 8. Influence of Ground Proximity on Flap Effectiveness at 60 degrees Deflection

It is obvious that blowing increases flap power in ground effect but the relationship is less clear. Figure 9 provides the differences, for like $\mathrm{h} / \mathrm{b}$, between the blowing and non-blowing conditions from the prior figure and reveals that proximities of 0.2 were necessary to produce notable effects. These were 
relatively invariant with angle of attack and resulted in a 5 to 7 percent increase in blowing effectiveness.

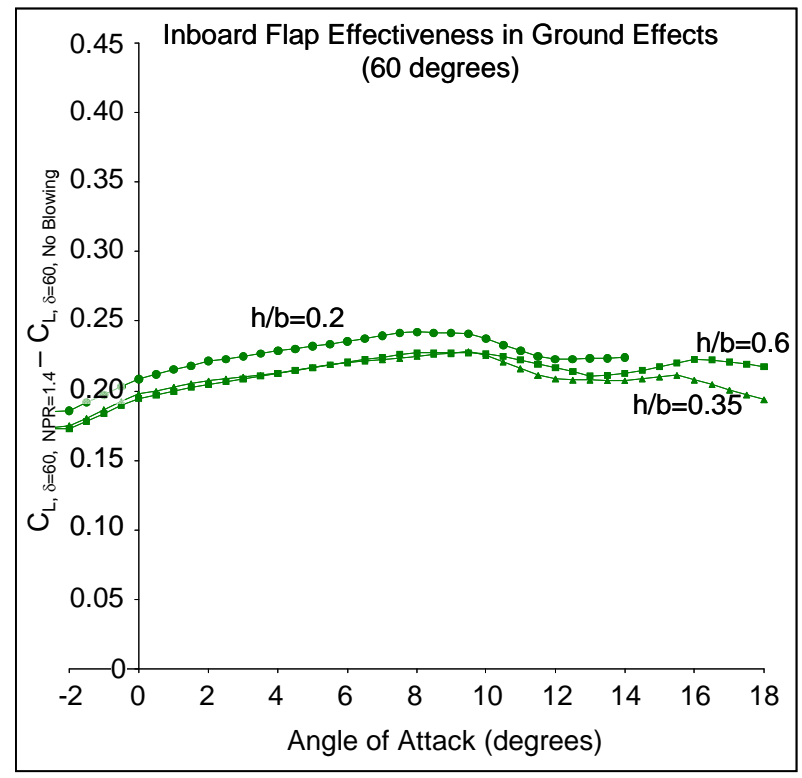

Figure 9. Observable Ground Proximity Effects Occurred at $0.2 \mathrm{~h} / \mathrm{b}$

\section{On-body Pressure Data}

On-body pressure tap data were obtained throughout the test. Pressure sensitive paint (PSP) was also used and is shown applied to the right side of the model in Figure 10. This complemented the pressure tap data and supported improving test techniques where significant jet Mach number and temperature variations are encountered as on the blown surfaces.

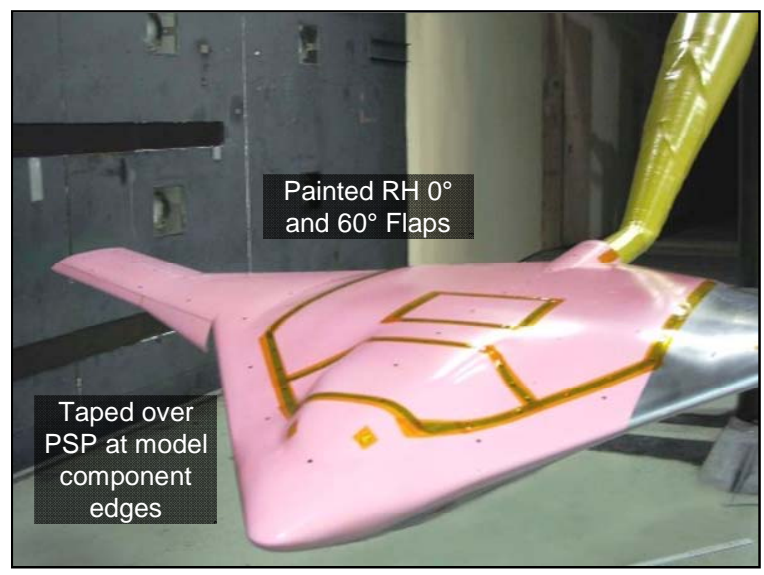

Figure 10. Pressure Sensitive Paint Applied to Model

The PSP technique was developed to make accurate determination of pressure distributions over aerodynamic surfaces based on an emitted optical signal from a luminescent coating. ${ }^{4,5}$ The optical signal emitted by the luminescent molecule (i.e., fluorescence and/or phosphorescence) is dependent on the oxygen concentration present in the surrounding medium. If the test surface under study is immersed in an atmosphere containing $\mathrm{O}_{2}$ (e.g., air), the recovered luminescence intensity can be described by the Stern-Volmer relationship ${ }^{6}$

$$
\frac{\mathrm{I}_{0}}{\mathrm{I}}=1+\mathrm{K}_{\mathrm{SV}} \mathrm{P}_{0_{2}}
$$

where $\mathrm{I}_{0}$ is the luminescence intensity in the absence of $\mathrm{O}_{2}$ (i.e., vacuum), $\mathrm{I}$ is the luminescence intensity at some partial pressure of oxygen $\mathrm{P}_{\mathrm{O} 2}$, and $\mathrm{K}_{\mathrm{SV}}$ is the Stern-Volmer constant.

For wind tunnel applications, a modified form of the Stern-Volmer equation that replaces the vacuum calibration $\left(\mathrm{I}_{0}\right)$ with a reference standard is used.

$$
\frac{\mathrm{I}_{\mathrm{REF}}}{\mathrm{I}}=\mathrm{A}(\mathrm{T})+\mathrm{B}(\mathrm{T}) \frac{\mathrm{P}}{\mathrm{P}_{\text {REF }}}
$$

Here $I_{\text {REF }}$ is the recovered luminescence intensity at a reference pressure, $\mathrm{P}_{\mathrm{REF}}$. The most common method used for data acquisition is a "steady-state" mode. During steady-state PSP experiments, $\mathrm{I}_{\mathrm{REF}}$ is typically acquired while the wind tunnel is off or at very low speed and $P_{R E F}$ is the static pressure when no wind is applied. Thus $\mathrm{I}_{\mathrm{REF}}$ is referred to as the "wind-off" intensity and $\mathrm{I}$ is the recovered luminescence intensity at sample pressure P. Since this data is collected at a specific condition in the wind tunnel, I is also referred to as the "wind-on" intensity. (A and $\mathrm{B}$ are temperature-dependent constants for a given PSP formulation and are usually determined before hand using laboratory calibration procedures.)

Excitation of the PSP was accomplished using $400 \mathrm{~nm}$ light provided by light emitting diode (LED) based arrays. The arrays were placed so that a fairly even illumination of the painted wing as well as the painted flaps could be achieved. Images were acquired using a pair of thermoelectrically-cooled, 14-bit digital CCD cameras with them positioned such that one camera would acquire images over the majority of the upper wing surface (including the 0 degrees flap case), while the second camera would focus on the deflected flaps as illustrated in Figure 11. 


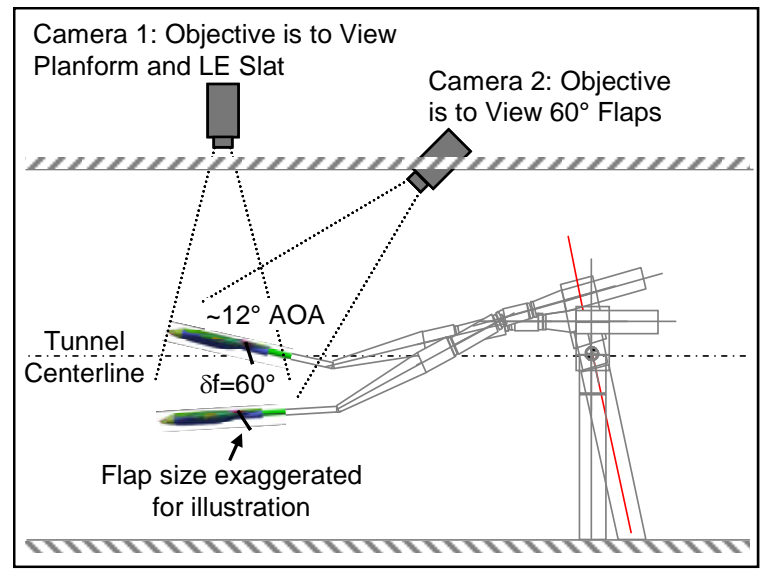

Figure 11. Two Cameras were Used for Obtaining PSP Readings on the Overall Planform and Deflected, Blown Flaps

Analysis of the PSP data was performed using software written by James Bell ${ }^{4}$ and others at NASA Ames Research Center. In general, all images were processed by first subtracting a background image from each image to account for stray background light. Using the fiducial marks in each image, a wind-on image was correlated to its respective windoff image (based on image time and proximity as well as angle of attack). This essentially "morphs" the wind-on image so that it is in the same image space as the wind-off image and is vital for correct analysis. The correlated wind-on image was then transformed to model coordinates using a direct linear transform method. ${ }^{4}$ The correlated wind-on image was then ratioed with its respective wind-off image $\left(I_{R E F} / I\right)$ and an in situ calibration with several pressure taps was used to create a pressure image. The in situ calibration was necessary to account for slight illumination differences between the wind-on and wind-off images as well as differences in temperature in the blowing jet regions. Based on run conditions, the pressure image was finally converted to $C_{P}$ and mapped to the surface grid of the model.

Sample results from the on-body pressure data for blowing off and 1.4 NPR are shown in Figures 12 and 13 respectively. The model's PSP image is provided along with the wing's corresponding chordwise pressure distribution at the buttline corresponding to the inboard flap's midspan (dashed line in image). There are a few artificial features in the images that represent the plenum cover standoffs that maintain the OML and slot geometry (periodic blue spots just forward of the blowing slot in Figure 12) and tape reflections (red in upper portion of Figure 13).

The pressure coefficients $\left(\mathrm{C}_{\mathrm{P}}\right)$ are plotted against the $\mathrm{X}$ locations normalized by the deployed slat leading-edge location $\left(\mathrm{X}_{0}\right)$ and the deflected trailingedge location $\left(\mathrm{X}_{\mathrm{C}}\right)$ of the 60 degrees flap. The pressure taps used for PSP calibration and the leading edge of the choke-plate chamber cover are also identified in this figure. The PSP calibration process required fitting the best line through the paint data around the taps. Since there are temperature variations in some parts of the images the fits may not be perfect.

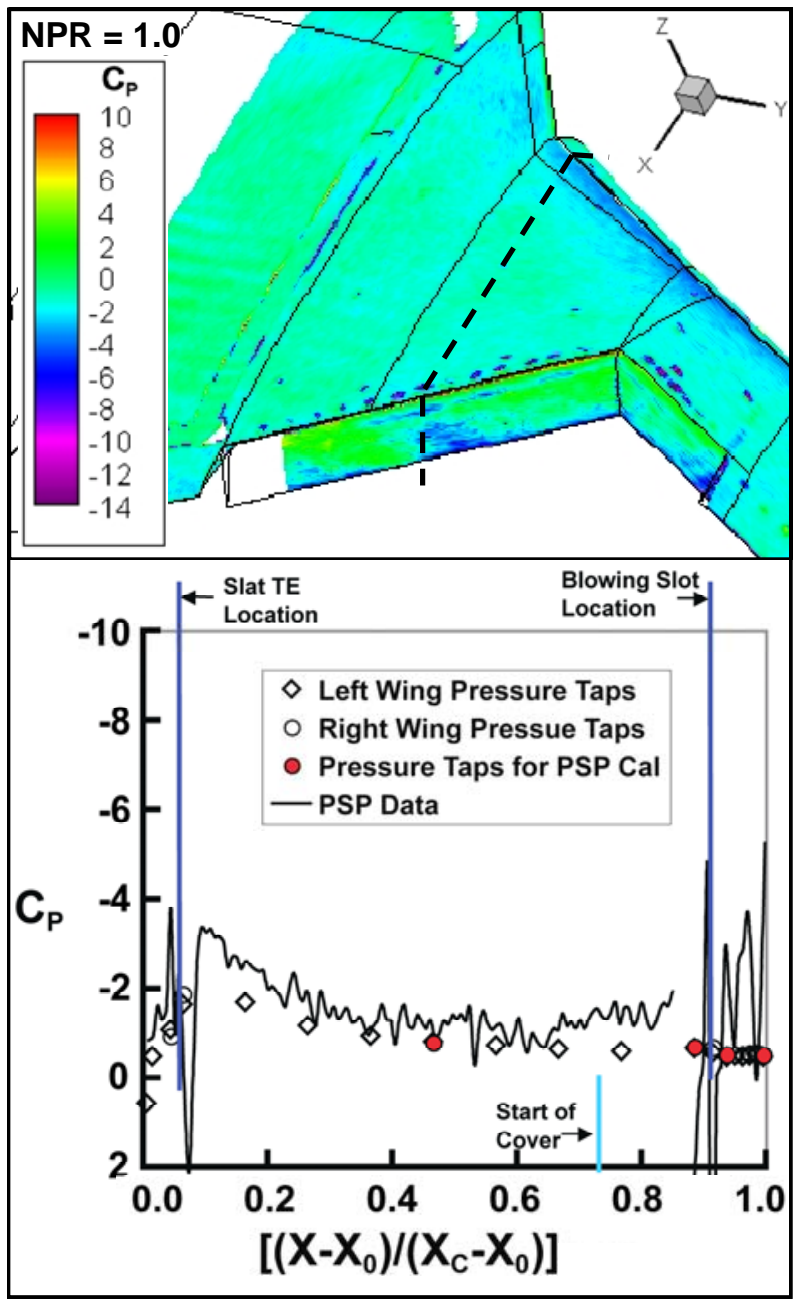

Figure 12. Blowing Off Pressure Data at 10 degrees AoA and Inboard Flap Deflected 60 degrees

Pressure tap measurements obtained on both the left wing and right wing agree well where the PSP data were taken. The only exception to this is the blowing case for the region just downstream of the blowing slot, where the difference is likely due to slight variations in the tap locations near highpressure gradients or in the slot height between the two sides.

During blowing off conditions PSP data indicate higher overall suction and substantial pressure 
oscillation both just upstream as well as on the flap. The oscillations are noticeable in the image as the changes from green to blue upon the flap surface. These oscillations near the blowing slot location are most likely anomalies in the PSP data due to the very small $\mathrm{C}_{\mathrm{P}}$ distributions that are occurring in this case where noise can play a major contributor. For this run, the PSP image was acquired over one hour after the last blowing condition, thus the flap would experience negligible temperature drift due to jet expansion compared with the rest of the model.

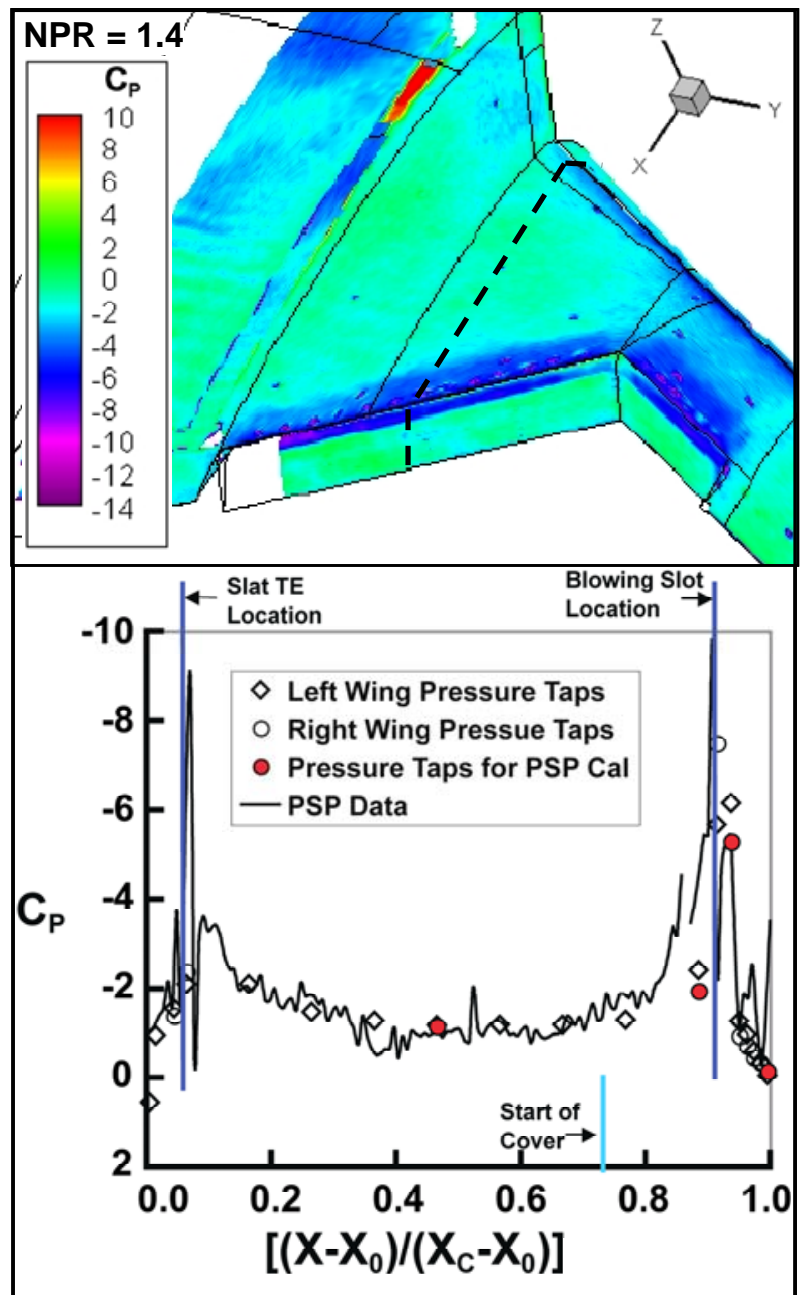

Figure 13. Blowing On Pressure Data at 10 degrees AoA and Inboard Flap Deflected 60 degrees

The low-speed limitation of PSP is well known, especially for separated flows. There were also some localized large oscillations of the PSP measurement most likely due to a combination of small registration and mapping errors associated with projecting the two camera views onto a single grid. These errors were observed just upstream of the blowing slot (coincident with the transition area between the two camera views) and have been removed.

During blowing on conditions (Figure 13), the wing's aerodynamic features appear uniform and well behaved. The peak suction regions behind the slat and aligned with the blowing slot are clearly pronounced but may be excessive when compared to the pressure tap data. Although the PSP and pressure tap measurements agree better for this condition the large spike in the suction pressure just downstream of the slat trailing edge and the discrepancy just upstream of the blowing slot are not fully understood. One would expect accelerated flow through the slat gap but the uncertainties associated with the significant gap or "break" on the model surface (area that is not well painted and/or illuminated) may introduce errors. While in front of the slot the discrepancy is pronounced, along the flap itself the agreement is much better.

From this image one can also see the strength of the outer wing panel. Pressure tap data reveal higher suction pressures in this region when compared to the inboard wing. The PSP results here were generally higher than the pressure tap results.

A number of lessons were learned in this application of PSP and the largest challenge relates to temperature changes that occur across the model due to the blowing jet. Temperature effects were especially noticeable in initial testing when the supply temperature was significantly different from the tunnel and model temperature. Specifically, the regions on the cover plate for the choke-plate chamber located just upstream of the blowing slot where it was difficult to successfully use PSP to measure accurate surface pressures. The temperature effects were prevalent in the early portions of the tests and then were minimized (but not eliminated) by careful monitoring of the temperatures. A detailed discussion of this topic are beyond the scope of this paper, however it will be addressed in a future report.

\section{Off-body Flow Field Survey}

An off-body flow field survey was made using a wake rake survey system to query the wake of the left wing. This system consisted of a 7-hole probe subsystem, containing eight 7 -hole probes with vertical spacing of one inch between probe tips, and the probe positioning sub-system as shown in Figure 14. The general technique used in this survey involved a standard method of defining a set of non-dimensional coefficients based on the location of the maximum of the seven $\mathrm{C}_{\mathrm{P}}$ readings from the probe. ${ }^{7,8}$

The following three model configurations were investigated with the probe system: $60^{\circ}$ flap and slaton at $10^{\circ} \mathrm{AOA}, 0^{\circ}$ flap without slat at $0^{\circ} \mathrm{AOA}$, and $60^{\circ}$ flap without slat at $0^{\circ} \mathrm{AOA}$. All configurations 
were at $0^{\circ}$ yaw angle. The first case has the most resolution in the survey grid and included several surveying stations in the downstream (X) direction. Flow features observed from the wake survey are briefly discussed in this paper for the first case but the research is more fully described in the 2008 paper by Lin, et al. ${ }^{9}$

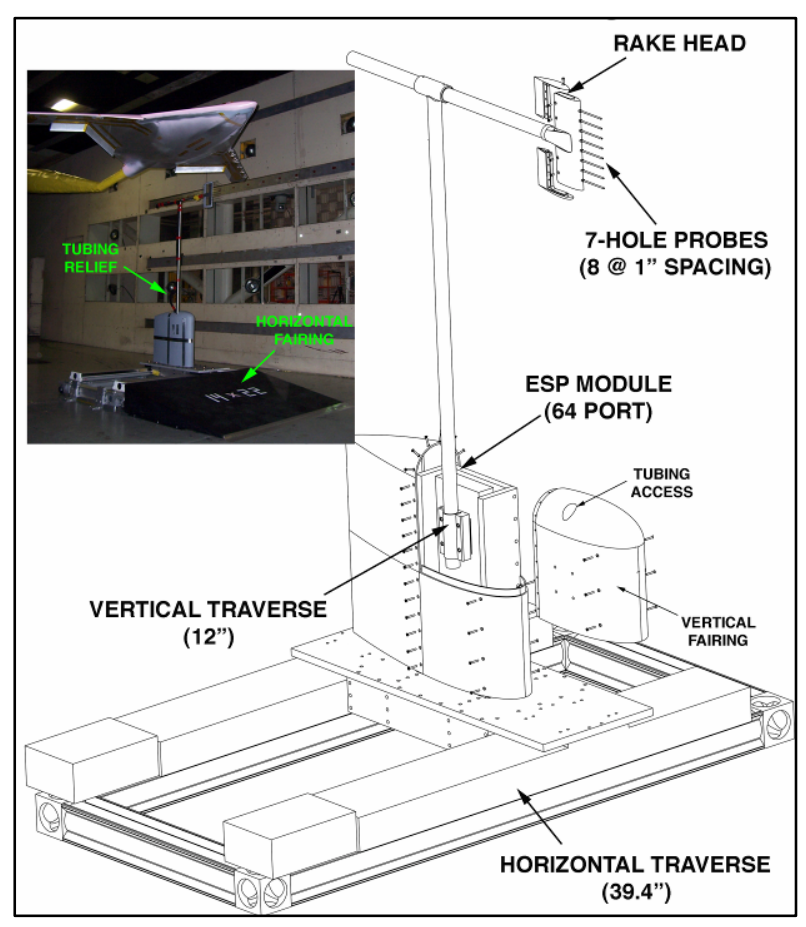

Figure 14. Wake Rake Survey System.

Model and wind tunnel coordinate systems were aligned when the model angle of attack was 0 degrees. To couple these coordinate systems the probes were initialized relative to a known location on the model. This position was coincident with the aft tip of the outboard wing panel. The seven-hole probe rake was moved in the tunnel coordinate system (streamwise, horizontal, and spanwise, i.e., $X$, $\mathrm{Y}$, and $\mathrm{Z}$ respectively). The rake was traversed to cover a plane 10 inches high (i.e. tunnel vertical axis) and 26 inches wide (i.e. tunnel horizontal or lateral axis), thus extending nearly to the innermost buttline of the inboard flap. The majority of the data were obtained with a fine grid spacing of 0.25 inch in both directions. Due to the sweep angles of the model's trailing edge, the data plane was not at a consistent position relative to the blowing slot. This would be a preference for future testing. Nevertheless the current data will prove useful in strengthening methods in computational fluid dynamics for this flow regime. As the angle-of-attack was changed to conduct different flow field measurement sets, the rake position relative to the model were not resolved for consistent model positions.

Flow-field results in terms of $\mathrm{Y}-\mathrm{Z}$ plane contours of the absolute velocity magnitude (Vmag) and the ratio of probe total pressure over freestream total pressure (Pt/Pto) are presented in Figure 15 at the end of this paper. The condition shown represents a 10 degrees angle of attack, NPR of 1.37, and all flaps at 60 degrees case. Several features are prominent in the figure. The concentrated high Vmag and Pt/Pto regions located at $Z$ of approximately 2 inches just downstream of the inboard flap reveal the significant effect of momentum addition due to the inboard blowing jet. A high degree of freestream flow turning is exhibited as the Vmag contours show high velocity above and below the inboard jet sheet. This is also seen in the vector field plot. The Vmag and total pressure contours show decaying levels outboard. This occurs for two reasons. With the blowing slot established as a constant height to chord-length ratio, the inboard flap slot height was maximum at the most inboard location and decreased until it reached the outboard flap where the height remained constant due to the constant chord, outboard wing section. Thus the most inboard location would by definition experience the largest momentum addition. Additionally, the reader is reminded that because the rake sweeps were made in the tunnel axis, as the rake moves outboard the distance downstream of the inboard flap jet increases. This would present an apparent decay in momentum addition. The outboard flap's jet sheet is considerably less prominent for these reasons.

Additionally, one can notice the vortical structures forming in the upper regions of the plane. These were not noticed in the PSP image of Figure 13 as, at angles of attack of 10 degrees or less, they were not strongly interacting with the surface conditions. Above these angles, and most prominently at angles of attack of 12 to 13 degrees the force data suggests notable interactions.

\section{Concluding Remarks}

The test summarized in this paper supported combined objectives of AFRL, NASA, and Northrop Grumman. It gathered data to mature an all-wing configuration and associated circulation control technologies that enable cruise efficient, short takeoff and landing systems. The model accomplished all of its requirements. The model's integrated blowing system proved very reliable and once temperature related effects on the balance were resolved, it proved to be very predictable too. The blowing control system ensured an efficient test as it was timely in establishing the desired test condition. The use of 
NASA's $14 \mathrm{ft}$. by $22 \mathrm{ft}$. wind tunnel and associated balance, air sting, rig, and air supply were the first of this type in nearly a decade. Although the overall arrangement was complex the test resulted in regaining a previously dormant capability in short order to support continued testing advancements in this research area.

The test itself produced a large collection of force and moment data, on-body pressure data, and off-body flow field measurements that will be used to refine the configuration and strengthen design tools. Northrop Grumman has built an aerodynamic database to conduct flight simulation studies of the design's features. An all-wing design poses a number of flight control challenges that when overcome will provide a level of cruise efficiency when combined with STOL performance previously not obtained. Finally, given the comprehensiveness of the test data, particularly as it relates to a specific three dimensional air vehicle configuration, will aid the CFD developmental efforts for high-lift wings with advanced circulation-control technologies.

\section{Ackownledgement}

The authors extend their special thanks to the staff and crew of the NASA Langley Research Center 14- by 22-Foot Subsonic Wind Tunnel and the AFRL/Northrop Grumman/NASA research team for their contributions during this project.

\section{References}

1. Kudirka, J. et al, A-6A Circulation Control Wing Flight Test Final Report, 13 April 1979.

2. Sellers III, W. L., Jones, G. S., Moore, M. D., "Flow Control Research at NASA Langley in Support of High-Lift Augmentation," AIAA-20026006.

3. Northrop, J. K, "The Development of AllWing Aircraft" given at the 35th Wilbur Wright Memorial Lecture in May 1947.

4. Bell, J. H., Schairer, E. T., Hand, L. A., and Mehta, R. D., 2001, "Surface Pressure Measurements Using Luminescent Coatings," Annu. Rev. Fluid Mech., vol. 33, pp. 155-206.

5. Liu, T. and Sullivan, J. P., 2004, Pressure and Temperature Sensitive Paints (Experimental Fluid Dynamics), Berlin: Springer-Verlag.

6. Lakowicz, J., 1999, Principles of Fluorescence Spectroscopy, Second Edition, New York: Kluwer Academic/Plenum Publishers, pp. 239242.
7. Johansen, E. S., Rediniotis, O. K., Jones, G.S., 2001, "The Compressible Calibration of Miniature Multi-Hole Probes," Journal of Fluids Engineering, vol. 123, no. 3, pp. 128-138.

8. Rediniotis, O. K., Hoang, N. T., and Telionis, D. P., 1993, "The Seven-Hole Probe: Its Calibration and Use," Forum on Instructional Fluid Dynamics Experiments, vol. 152, pp. 21-26.

9. Lin, J. C., Jones, G. S., Allan, B. G., Westra, B. K., Collins, S. W., Zeune, C. H., "Flow-Field Measurement of a Hybrid Wing Body Model with Blown Flaps," presented at the AIAA Applied Aerodynamics Conference, 18-21 August 2008. 


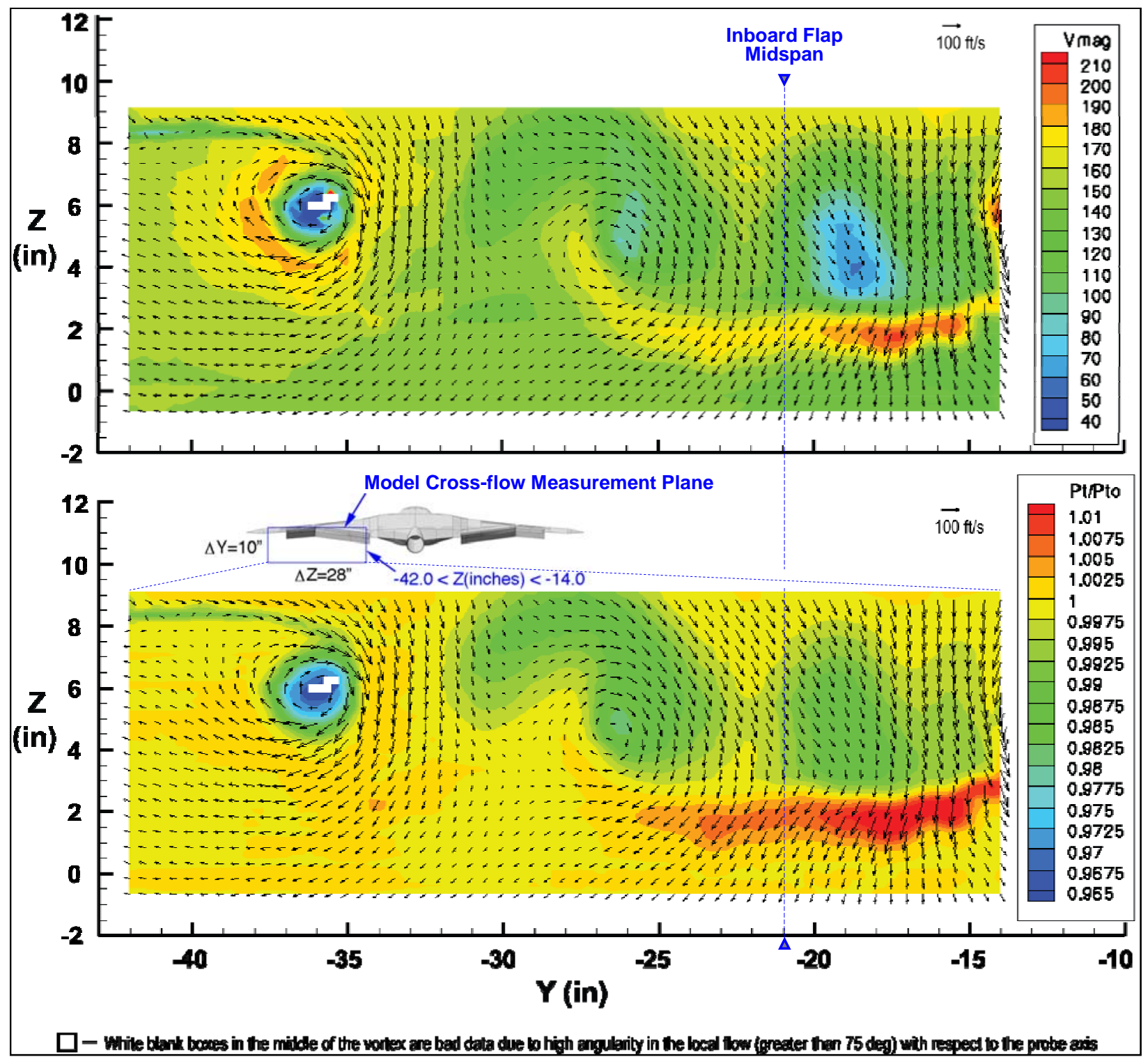

Figure 15. $\mathrm{V}_{\text {mag }}$ and $\mathrm{P}_{\mathrm{t}} / \mathrm{P}_{\text {to }}$ Contours in $\mathrm{Y}-\mathrm{Z}$ Plane Behind Blown Flaps (Test Conditions: 0.143 $\mathrm{M}_{\infty}$, Slats on, 60 Degrees Flap Deflection, 10 Degrees Angle of Attack, 1.37 NPR, Run 2228) 